
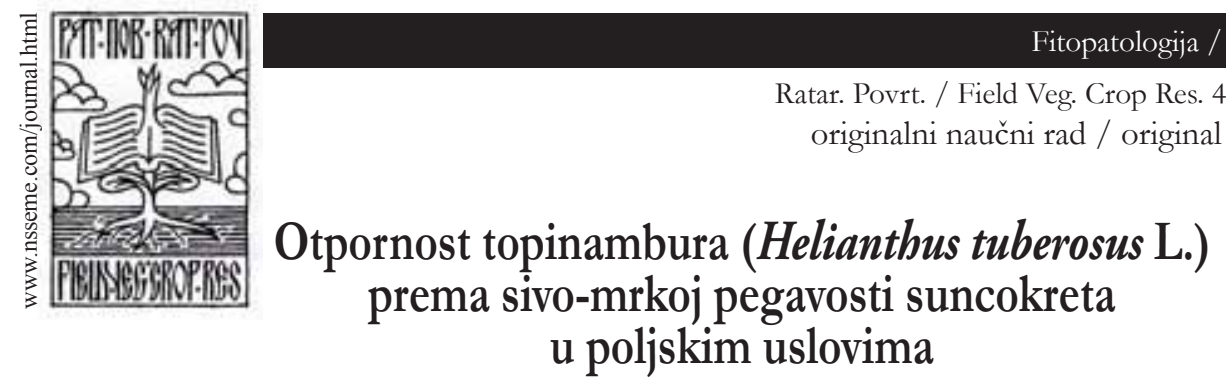

\author{
Sreten Terzić $\cdot$ Boško Dedić $\cdot$ Jovanka Atlagić $\cdot$ Vladimir Miklič
}

received / primljeno: 27.09.2010. accepted / prihvaćeno: 19.11.2010.

(C) 2011 IFVC

\begin{abstract}
Izvod: Topinambur je višegodišnja vrsta suncokreta poreklom iz centralnog dela Severne Amerike. Ova vrsta je prepoznata kao potencijalni izvor otpornosti na neke od ekonomski značajnih bolesti koje se javljaju kod gajenog suncokreta kao što je sivo-mrka pegavost stabla. U ogledu je korišćena ukupno 141 populacija topinambura na karantinskoj parceli Instituta za ratarstvo i povrtarstvo u Novom Sadu. Inokulisane su biljke u stalnom zasadu i u oglednoj parceli na kojoj su sađene krtole izolatima Phomopsis helianthi sa Rimskih Šančeva. Nakon sedam dana gajenja na PDA (Potato-Dextrose Agar) podlozi, isečci micelije gljive Phomopsis helianthi su stavljani na vrh lista i potom prekrivani folijom. Napredovanje bolesti je mereno u pravilnim vremenskim intervalima. Praćen je intenzitet prirodne infekcije i zabeležena pojava ostalih bolesti. Utvrđene su značajne razlike u brzini napredovanja bolesti između pojedinih populacija. Populacije TUB2046, TUB2062, TUB CG 65 su pokazale najveću otpornost.
\end{abstract}

Ključne reči: otpornost, Phomopsis helianthi, topinambur

\section{Uvod}

Topinambur je višegodišnja vrsta suncokreta poreklom iz centralnog dela Severne Amerike koja je početkom XVII veka prenešena u Evropu. On pripada obimnom i polimorfnom rodu Helianthus L. u okviru kojeg su Schilling i Heiser (1981) opisali 49 vrsta. U odnosu na većinu gajenih biljaka, topinambur je domaćin za mali broj bolesti i štetočina koje ga mogu ugroziti. Najveće gubitke u prinosu uzrokuju gljivična ili bakterijska oboljenja. Od gljiva značajne štete mogu uzrokovati Puccinia belianthi Schw. i Sclerotium rolfsii Sacc. Sclerotinia sclerotiorum (Lib) de Bary, koja je široko rasprostranjena i napada stablo, koren i krtole topinambura. Može da uzrokuje rano uginuće biljke, ali šire zaraze nisu česte (Kays \& Nottingham 2007).

Genetski resursi su od značaja za svaki oplemenjivački program. Topinambur je prepoznat kao potencijalni izvor otpornosti na neke od ekonomski značajnih bolesti koje se javljaju kod gajenog suncokreta, kao što su plamenjača i bela trulež

S. Terzić $(\varangle) \cdot$ B. Dedić $\cdot J$. Atlagić $\cdot$ V. Miklič

Institut za ratarstvo i povrtarstvo, Maksima Gorkog 30, 21000 Novi Sad, Srbija

e-mail: sreten.terzic@ifvcns.ns.ac.rs cvasti, ali i volovod kao parazitna cvetnica. Zbog toga se vrše međuvrsna ukrštanja sa gajenim suncokretom radi prenosa poželjnih osobina u vidu otpornosti na bolesti ili insekte (Seiler 1992). Topinambur je testiran i kao izvor otpornosti na sivo-mrku pegavost stabla suncokreta (prouzrokovač Phomopsis (Diaporthe) helianthi) i pokazalo se da postoje populacije koje bi mogle da se iskoriste za oplemenjivanje gajenog suncokreta (Dozet et al. 1992). Pojava ove gljive i značajne štete su prvi put zabeleženi u Srbiji početkom osamdesetih godina (Mihaljčević i sar. 1980).

Komercijalni hibridi sa visokim nivoom tolerantnosti prema $P$. helianthi dostupni su od kada je Škorić (1985) došao do visoko tolerantnih inbred linija dobijenih ukrštanjem gajenog suncokreta sa vrstom $H$. tuberosus, vrste $H$. argophyllus sa populacijom H. annuus Armavirski 9345 i jedne linije koja potiče od lokalne populacije iz Maroka. Na bazi tih inbred linija, on je razvio visoko toleranthe hibride: NS-H-43, NS-H-44 i NS-H-45 (Škorić 1985).

Danas je $P$. helianthi rasprostranjen u mnogim zemljama i odlikuje se velikom varijabilnošću izolata u pogledu fenotipa i agresivnosti (Viguie et al. 1999). Studije sprovedene u Francuskoj na izolatima ove gljive iz poslednje epidemije 1997, korišćenjem AFLP markera (Amplified Fragment 
Length Polymorphism) potvrdile su pretpostavke o genetskoj varijabilnosti na osnovu čega su autori istraživanja izneli pretpostavku o mogućem smanjenju osetljivosti pojedinih populacija prema fungicidima i prevazilaženje postojećeg nivoa otpornosti (Says-Lesage et al. 2002). Pri poređenju izolata Yu 4 i Yu 12 od kojih je Yu 12 poreklom iz epidemije 1997. Jocić i sar. (2004) su ustanovili da između njih nema značajnih razlika i da je epidemija iz 1997. u dolini reke Dunav rezultat povoljnih klimatskih uslova za razvoj bolesti.

Pošto postojeći izvor otpornosti na $P$. helianthi funkcioniše već 25 godina i postoji realna opasnost da bude prevaziđen, cilj ovog rada je pronalaženje novih izvora otpornosti prema $P$. helianthi. Zbog izražene genetske varijabilnosti unutar vrste (Atlagić i sar. 2006) kao i činjenice da je potvrđeno postojanje otpornosti u ranijim istraživanjima (Škorić 1985) testirane su populacije topinambura na otpornost prema $P$. belianthi.

\section{Materijal i metod}

Ogled je izveden na lokalitetu Rimski Šančevi, na karantinskoj parceli Odeljenja za uljane kulture Instituta za ratarstvo i povrtarstvo u Novom Sadu. U ogledu je korišćena ukupno 141 populacija topinambura. Među njima je 27 gajenih sorti (TUB BP), 111 divljih populacija koje su uključene u kolekciju putem sakupljačkih ekspedicija u Sjedinjenim Američkim Državama (38) i Crnoj Gori (73) i tri lokalne populacije (Tab. 1. i 2). Biljke su gajene 2007. godine na dva načina, u oglednoj parceli i u stalnom zasadu. U oglednoj parceli je svaka populacija gajena u po jednom redu dužine $7,5 \mathrm{~m}$ sa po 15 biljaka. Setva je izvršena presađivanjem krtola u deo karantinske parcele agrotehnički pripremljene za gajeni suncokret, ukupne površine 1,2 ha. Prihrana zemljišta je izvršena sa $300 \mathrm{~kg} \mathrm{ha}{ }^{-1}$ NPK đubriva tipa 15:15:15. U stalnom zasadu su populacije gajene u parcelicama širine $0,5 \mathrm{~m}$ i dužine $3 \mathrm{~m}$ bez kontrole broja biljaka unutar parcelice, u okviru kolekcije divljih vrsta suncokreta. Prihrana zemlijišta je izvršena sa $300 \mathrm{~kg} \mathrm{ha}^{-1}$ NPK đubriva tipa 15:15:15 rasutog po površini. Uređivanje parcelica je vršeno u proleće pre pojave izdanaka, a navodnjavanje po potrebi sistemom za navodnjavanje.

Infekcija je vršena po metodi Tourvieille de Labrouhe et al. (1988). Inokulisano je po dva lista na po pet biljaka za svaku ispitivanu populaciju. Inokulisani su listovi koji se nalaze na polovini ukupne visine stabla.

Kao inokulum je korišćena micelija gljive $P$. helianthi na PDA podlozi stara 4 dana. Zbog razlike u fazama vegetacije između populacija topinam- bura, listovi testiranih biljaka su inokulisani sukcesivno u fazi neposredno pre početka cvetanja.

Intenzitet infekcije je meren 14 dana nakon inokulacije određivanjem napretka gljive preko glavnog lisnog nerva ka lisnoj dršci i izražavan je u milimetrima, čime je dobijena apsolutna ocena intenziteta infekcije. Dužina liske je iskorišćena za dobijanje relativne ocene otpornosti kao procenta liske zahvaćene gljivom/pegom. $\mathrm{Na}$ istoj parceli su kao kontrole korišćene osetljiva inbred linija gajenog suncokreta NSL1 i tolerantna inbred linija NSL2. Ocena biljaka koje nisu inokulisane je vršena prema skali od 0 do 10 (Jocić i sar. 2004) na po 5 biljaka po populaciji.

Zabeleženo je i prisustvo ostalih bolesti u toku vegetacije na svim biljkama radi ocene poljske otpornosti za oba tipa gajenja.

\section{Rezultati i diskusija}

Količina padavina 2007. godine je bila u nivou proseka ili veća kao u februaru, maju i periodu od avgusta do novembra, ali je april bio bez padavina. Temperature su se kretale oko prosečnih vrednosti. Apsolutni temperaturni maksimum na nivou mesečne dekade od $42^{\circ} \mathrm{C}$ je zabeležen u julu. Klimatski uslovi što se tiče razvoja $P$. helianthi su bili relativno nepovoljni zbog perioda sa povišenim temperaturama.

$\mathrm{Na}$ linijama koje su korišćene kao kontrole zabeležen je različit intenzitet infekcije, koji je na osetljivoj kontroli NSL1 je posle 14 dana iznosio $62 \mathrm{~mm}$, a na tolerantnoj NSL2 $34 \mathrm{~mm}$.

Iako su rezultati istraživanja pokazali da je došlo do infekcije kod svih testiranih populacija, evidentno je postojanje visokog nivoa tolerantnosti. Nakon 14 dana od inokulacije, samo kod 17 od 141 testirane populacije procenat liske sa simptomima bolesti je iznosio više od $50 \%$ (Tab. 1. i 2).

$\mathrm{Na}$ kontrolnom uzorku populacija, deo liske sa simptomima se povećao za 15\% nakon 28 dana od inokulacije, što je bilo dvostruko manje od prosečnog napretka za prvih 14 dana (37\%). To ukazuje na usporenje napredovanja patogena što objašnjava i krajnji rezultat da do kraja vegetacije nije došlo do pojave simptoma na stablu. Rezultati posle 28 dana su bili nekompletni jer su pojedine populacije zbog granatosti ranije odbacile listove sa centralnog stabla zbog čega ovi rezultati nisu prikazani.

U ogledu je zabeleženo ukupno dvadeset od testirane 141 populacije sa manje od 25\% liske zahvaćenih simptomima bolesti, od čega je 13 od 73 poreklom iz Crne Gore (Tab. 1), 6 od 38 iz SAD-a i 1 od 27 gajenih sorti (Tab. 2). 
Tabela 1. Reakcija populacija topinambura poreklom iz Crne Gore na Phomopsis helianthi Munt.-Cvet. Table 1. Reaction of topinambour populations from Montenegro to Phomopsis helianthi Munt.-Cvet.

\begin{tabular}{|c|c|c|c|c|c|}
\hline $\begin{array}{l}\text { Populacija } \\
\text { Population }\end{array}$ & $\begin{array}{l}\text { intenzitet } \\
\text { infekcije } \\
\text { infection } \\
\text { intensity } \\
(\mathrm{mm})\end{array}$ & $\begin{array}{c}\% \text { liske sa } \\
\text { simptomima } \\
\text { bolesti } \\
\% \text { of leaf } \\
\text { with disease } \\
\text { symptoms }\end{array}$ & $\begin{array}{l}\text { Populacija } \\
\text { Population }\end{array}$ & $\begin{array}{l}\text { intenzitet } \\
\text { infekcije } \\
\text { infection } \\
\text { intensity } \\
(\mathrm{mm})\end{array}$ & $\begin{array}{c}\% \text { liske sa } \\
\text { simptomima } \\
\text { bolesti } \\
\% \text { of leaf } \\
\text { with disease } \\
\text { symptoms }\end{array}$ \\
\hline TUB CG 3 & 62 & 27 & TUB CG 41 & 86 & 41 \\
\hline TUB CG 4 & 64 & 38 & TUB CG 42 & 44 & 21 \\
\hline TUB CG 5 & 44 & 21 & TUB CG 43 & 75 & 37 \\
\hline TUB CG 6 & 54 & 25 & TUB CG 44 & 73 & 34 \\
\hline TUB CG 7 & 60 & 30 & TUB CG 45 & 81 & 47 \\
\hline TUB CG 8 & 43 & 19 & TUB CG 46 & 91 & 42 \\
\hline TUB CG 9 & 79 & 59 & TUB CG 47 & 88 & 45 \\
\hline TUB CG 10 & 58 & 28 & TUB CG 48 & 68 & 39 \\
\hline TUB CG 11 & 67 & 30 & TUB CG 49 & 75 & 35 \\
\hline TUB CG 12 & 58 & 28 & TUB CG 50 & 71 & 40 \\
\hline TUB CG 13 & 46 & 22 & TUB CG 51 & 81 & 38 \\
\hline TUB CG 14 & 36 & 24 & TUB CG 52 & 79 & 35 \\
\hline TUB CG 15 & 46 & 22 & TUB CG 53 & 93 & 45 \\
\hline TUB CG 16 & 68 & 31 & TUB CG 54 & 78 & 39 \\
\hline TUB CG 17 & 62 & 31 & TUB CG 55 & 36 & 21 \\
\hline TUB CG 18 & 68 & 32 & TUB CG 56 & 72 & 43 \\
\hline TUB CG 19 & 106 & 75 & TUB CG 57 & 88 & 40 \\
\hline TUB CG 20 & 35 & 14 & TUB CG 58 & 69 & 36 \\
\hline TUB CG 21 & 39 & 21 & TUB CG 59 & 74 & 45 \\
\hline TUB CG 22 & 54 & 27 & TUB CG 60 & 76 & 35 \\
\hline TUB CG 23 & 52 & 26 & TUB CG 61 & 61 & 35 \\
\hline TUB CG 24 & 65 & 32 & TUB CG 62 & 39 & 20 \\
\hline TUB CG 25 & 43 & 22 & TUB CG 63 & 70 & 31 \\
\hline TUB CG 26 & 63 & 36 & TUB CG 65 & 19 & 10 \\
\hline TUB CG 27 & 65 & 44 & TUB CG 66 & 73 & 36 \\
\hline TUB CG 28 & 56 & 30 & TUB CG 67 & 64 & 29 \\
\hline TUB CG 69 & 64 & 32 & TUB CG 69 & 80 & 36 \\
\hline TUB CG 70 & 77 & 34 & TUB CG 70 & 51 & 25 \\
\hline TUB CG 72 & 51 & 27 & TUB CG 72 & 57 & 28 \\
\hline TUB CG 75 & 70 & 30 & TUB CG 75 & 52 & 25 \\
\hline TUB CG 33 & 68 & 32 & TUB CG 76 & 86 & 42 \\
\hline TUB CG 34 & 78 & 37 & TUB CG 77 & 84 & 48 \\
\hline TUB CG 36 & 81 & 38 & TUB CG 78 & 37 & 19 \\
\hline TUB CG 37 & 82 & 37 & TUB CG 79 & 56 & 28 \\
\hline TUB CG 38 & 79 & 38 & TUB CG 80 & 59 & 33 \\
\hline TUB CG 39 & 79 & 37 & NSL1 & 62 & 37 \\
\hline TUB CG 40 & 81 & 40 & NSL2 & 34 & 20 \\
\hline
\end{tabular}


Tabela 2. Reakcija divljih populacija iz SAD-a i gajenih sorti topinambura na Phomopsis helianthi Munt.-Cvet. Table 2. Reaction of wild populations from USA and topinambour cultivars to Phomopsis helianthi Munt.-Cvet.

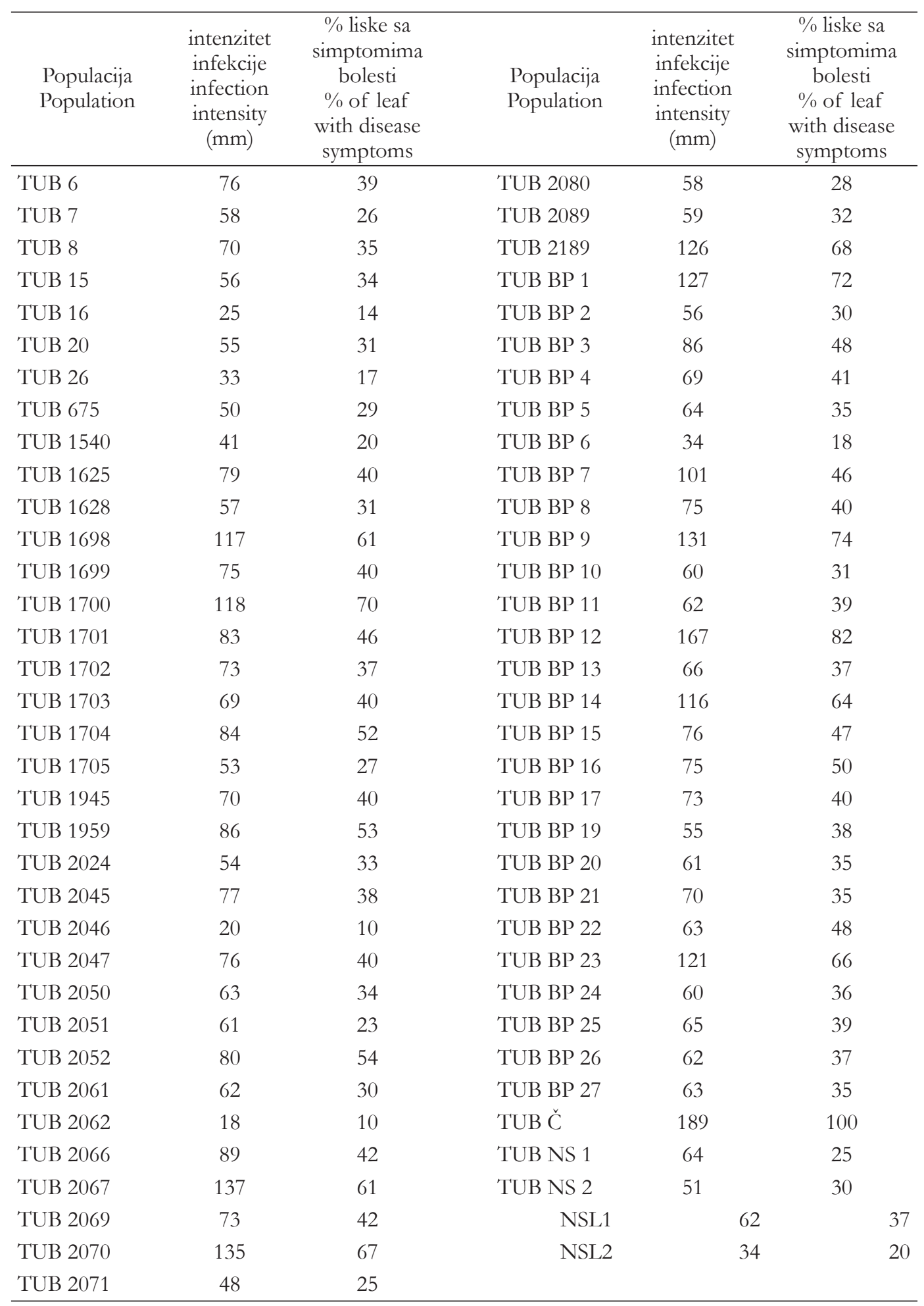


Ukupno šest populacija je imalo intenzitet infekcije isti ili manji od tolerantne kontrole NSL2. Od tih šest populacija četiri su bile poreklom iz SAD-a. Veći ili isti intenzitet infekcije u odnosu na osetljivu kontrolu je imalo 92 populacije, od čega je 45 od 73 poreklom iz Crne Gore, 22 od 38 iz SAD-a, 20 od 27 gajenih sorti i 2 od 3 lokalne populacije. Ako bi se po poreklu uporedio udeo populacija osetljivijih od osetljive kontrole populacije poreklom iz Crne Gore i SAD-a su približno iste sa 58\% i 61\% dok kod gajenih sorti taj udeo iznosi $74 \%$.

Testom otpornosti na sivo-mrku pegavost stabla populacija jednogodišnje vrste suncokreta $H$. petiolaris, autori Caseres et al. (2007) su ustanovili pojavu infekcije na svim inokulisanim biljkama sa prosečnim intenzitetom infekcije od $22 \mathrm{~mm}$, a označili su kao visoko tolerantne populacije sa intenzitetom infekcije do $17 \mathrm{~mm}$, odnosno one kod kojih je do 23\% liske imalo simptome bolesti. Samo tri populacije (TUB2046, TUB2062, TUB CG 65) su imale intenzitet infekcije manji od 22 $\mathrm{mm}$ (Tab. 1. i 2). Broj populacija sa procentom liske sa simptomima manjim od $23 \%$ je bio veći jer su liske vrste $H$. tuberosus skoro dvostruko veće od liski vrste $H$. petiolaris (Heiser et al. 1969).

Od ostalih bolesti su na osetljivoj kontroli zabeležene: mrka pegavost lišća (prouzrokovač Alternaria helianthi), crna pegavost stabla (prouzrokovač Phoma macdonaldii) i pepelnica (prouzrokovač Erysiphe chichoracearum). Ispitivanje poljske otpornosti je uključeno u ovaj rad zbog povećanog interesa za topinambur kao gajenu biljku (Seiler et al. 2006; Kays \& Nottingham 2007) i malog broja literaturnih izvora koji opisuju bolesti i štetočine koje bi ga mogle ugroziti u agroekeološkim uslovima gajenja na teritoriji Srbije.

$\mathrm{U}$ oceni poljske otpornosti topinambura konstatovani su simptomi pepelnice koja se pojavila pri kraju faze cvetanja na 99 od 141 populacije u oglednoj parceli i 71 od 95 opažanih u stalnom zasadu. Od ostalih patogena najčešća je bila bela trulež korena koja se javila samo kod biljaka u oglednoj parceli, a zabeležena je na ukupno 16 populacija sa učestalošću od $7 \%$ do $30 \%$ biljaka po populaciji. Bela trulež korena se javila na pojedinim biljkama, kako se inače i javlja na parcelama sa topinamburom, gde retko zahvata veću površinu (Kays \& Nottingham 2007). Crna pegavost stabla je zabeležena na 4 populacije na oglednoj parceli sa učestalošću od $7 \%$ do $40 \%$.

U oglednoj parceli se osim pepelnice pojavila sivo-mrka pegavost lista na 6 populacija sa učestalošću od $7 \%$ do $27 \%$ i sivo-mrka pegavost stabla na populaciji TUB BP 12. U stalnom zasadu su simptomi iste bolesti zabeleženi samo na populaciji TUB1625. Manja učestalost pojave sivo-mrke pegavosti putem prirodne infekcije može se objasniti nedostatkom prouzrokovača bolesti, ali i relativno nepovoljnim uslovima za njegov razvoj, pogotovo u parcelicama stalnog zasada gde je relativna vlažnost vazduha bila niža. Istraživanjima na gajenom suncokretu je potvrđeno da su agrotehničke mere takođe važne za suzbijanje $P$. belianthi jer gustina setve pozitivno utiče na povećanu relativnu vlažnost vazduha u usevu, a samim tim i na povećanu učestalost infekcija lista i lezija stabla (Debaeke \& Moinard 2010). Pored toga, najbolji način za kontrolu ove gljive jeste gajenje otpornih hibrida (Mihaljčević i sar. 1982).

\section{Zaključak}

Velika genetska varijabilnost unutar kolekcije topinambura se iskazala kroz značajne razlike u intenzitetu napredovanja bolesti između pojedinih populacija. Ustanovljeno je da 18 od 141 testirane populacije spada u grupu visoko tolerantnih prema sivo-mrkoj pegavosti i da bi se kao takve mogle upotrebiti u oplemenjivanju gajenog suncokreta.

Zbog većeg udela visoko tolerantnih populacija u grupi iz SAD-a ona bi se mogla označiti kao interesantnija u odnosu na ostale grupe za dalji rad na traženju novih izvora otpornosti uz populacije poreklom iz Crne Gore. Populacije TUB2046, TUB2062 i TUB CG 65 su pokazale najveću tolerantnost prema prouzrokovaču sivomrke pegavosti suncokreta $P$. helianthi. 


\section{Literatura}

Atlagić J, Terzić S, Škorić D, Marinković R, Vasiljević Lj, Panković D (2006): The wild sunflower species collection in Novi Sad. Helia 44: 55-64

Caseres C, Castano F, Rodriguez R, Ridao A, Salaberry T, Echeveria $\mathrm{M}$, Colabelli M (2007): Phomopsis resistance on leaves and stems of Helianthus petiolaris. Helia, 47: 213-218

Debaeke P, Moinard J (2010): Effect of crop management on epidemics of phomopsis stem canker (Diaporthe helianthi) for susceptible and tolerant sunflower cultivars. Field Crops Res. 115: 50-60

De Labrouhe T, Vear F, Pelletier C (1988): Use of two mycelium tests in breeding sunflower resistant to Phomopsis. 110114. In Proc. 12th Int. Sunflower Conf., Novi Sad, Serbia. 25-29 July. Int. Sunflower Assoc., Paris, France

Dozet B M, Atlagic J, Skoric D (1992): Sources of resistance to Diaporthe/Phomopsis helianthi and their use in sunflower breeding applying the in vitro embryo culture. p. 1449-1454. In Proc. 13th Int. Sunflower Conf., Pisa, Italy. 7-11 September. Int. Sunflower Assoc., Paris, France

Gulya T J, Maširević S (1991): Common names for plant diseases: sunflower (Helianthus annuus L.) and Jerusalem artichoke (Helianthus tuberosus L.). Plant Dis.75: 230

Heiser Ch B, Smith D M, Clevenger S B, Martin W C (1969): The North American Sunflowers (Helianthus). Mem. Torrey Bot. Club, 22: 219

Jocić S, Lačok N, Miklič V, Škorić D, Griveau Y (2004): Testing two isolates of Diaporthe/Phomopsis helianthi in a population of sunflower recombinant inbred lines. Helia 41: 129-136
Kays S J, Nottingham S F (2007): Biology and chemistry of Jerusalem artichoke (Helianthus tuberosus L.). CRC press, Boca Raton, FL, 478

Mihaljčević M, Petrov M, Muntanola-Cvetković M (1980): Phomopsis sp. - a new parasite of sunflower in Yugoslavia, Savremena polj. 11-12: 531-540

Mihaljčević M, Muntanola-Cvetković M, Petrov M (1982): Further studies on the sunflower disease caused by Diaporthe (Phomopsis) helianthi and possibilities of breeding for resistance. in: Int. Sunflower Conference (10th), Surfers Paradise, Australia, Paris: Int. Sunflower Association, 157-159

Says-Lesage V, Roeckel-Drevet P, Viguie A, Tourvieille J, Nicolas P, Tourvieille de Labrouhe D (2002): Molecular variability within Diaporthe/Phomopsis belianthi from France. Phytopathol. 92: 308-313

Schiling E E, Heiser Ch B (1981): Infrageneric classification of Helianthus (Compositae). Taxon 30: 393-403.

Seiler G J (1992): Utilization of wild sunflower species for the improvement of cultivated sunflower. Field Crops Res. 30: 195-230

Seiler G J, Campbell L G (2006): Genetic variability for mineral concentration in the forage of Jerusalem artichoke cultivars. Euphytica 150: 281-288

Škorić D (1985): Sunflower breeding for resistance to Diaporthe/Phomopsis helianthi Munt. -Cvet. et al. Helia 8: 21-24

Viguie A, Vear F, Tourvieille de Labrouhe D (1999): Interactions between French isolates of Phomopsis/Diaporthe helianthi Munt.-Cvet. et al. and sunflower (Helianthus annuиs L.) genotypes, Europ. Plant Patho. 105: 693-702

\title{
Resistance of Topinambour (Helianthus tuberosus L.) to Sunflower Stem Canker in Field Conditions
}

\author{
Sreten Terzić $\cdot$ Boško Dedić $\cdot$ Jovanka Atlagić $\cdot$ Vladimir Miklič
}

Institute of Field and Vegetable Crops, Maksima Gorkog 30, 21000 Novi Sad, Serbia

\begin{abstract}
Summary: Topinambour is a perennial species originating from central part of North America. This species is known to be a potential source of resistance to some diseases of cultivated sunflower like stem canker. In this research we evaluated 141 populations of Helianthus tuberosus from the collection of Institute of Field and Vegetable Crops in Novi Sad. Plants in the collection field and in the experimental field were artificially inoculated using Phomopsis helianthi isolate from Rimski Šančevi. After seven days of growing on PDA (Potato-Dextrose Agar) medium, mycelial plugs were placed on leaf tip and wrapped with aluminum foil. Disease progress was measured in regular intervals. Occurrence of natural infections was also evaluated and all diseases were noted. As a result of this survey significant differences were detected among populations regarding disease intensity. Out of all assessed populations those labeled as TUB2046, TUB2062 and TUB CG 65 were most resistant.
\end{abstract}

Keywords: Phomopsis helianthi, resistance, topinambour 